LESSON 53

Personal business letters

Letter 23

PAPER: A5 (148 × $210 \mathrm{~mm})$. MARGINS: Suitable.

TARGET TIME: 10 minutes.

Turn up 4 single lines before starting this personal business letter.

After typing the close turn up 5 single lines to give room to sign the letter and type the name of the person sending it.

Letter 24

PAPER: A5 $(148 \times 210 \mathrm{~mm})$.

MARGINS: Suitable.

TARGET TIME: 10 minutes.

Type Enc. 2 single lines below the typed name of the person sending the letter.

UNIT 14
If you want to type a letter to a business firm and do not have a headed sheet of paper, you will type your address at the head of the sheet. It can go in one of three places. You could centre each line at the head of the sheet. When using A4 paper, turn up 7 single lines before you start; when using A5 paper, turn up 4 single lines.

1. Centre this address on a sheet of $A 5$ paper $(148 \times 210 \mathrm{~mm})$. Turn up 4 lines.

$$
\begin{gathered}
62 \text { Oxford Road, } \\
\text { Coventry, } \\
\text { warwickshire. } \\
\text { CO2 30R }
\end{gathered}
$$

2. You could type your address at the left-hand margin. Type this address on a sheet of A5 paper $(148 \times 210 \mathrm{~mm})$. Turn up 4 lines before you start.

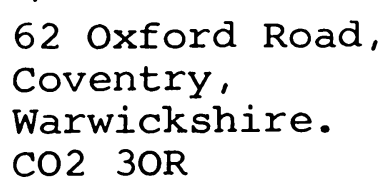

3. If you were going to type the letter in the semi-blocked style (Lesson 82) you might type your address on the right-hand side of the sheet, 4 or 7 single lines from the top, depending on its size. You must backspace the longest line from the right-hand margin, once for each letter and space.

Set $a$ tab at this point and start all the lines from here.

Type this address on a sheet of A5 paper $(148 \times 210 \mathrm{~mm})$.

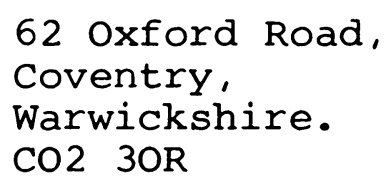

62 Oxford Road, Coventry, Warwickshire. CO2 3OR

Once you have typed the address of the person sending the letter on the sheet you can start the letter as usual, although you would not expect to type a reference. The date can go in its normal position, 3 single lines below the last line of the address of the person sending the letter. Turn up 3 single lines after the inside address before starting the letter.

From: 29 Cricket Lane, Kidderminster, Worcs. To-day's date

To: Quality Cards Limited, Oaken Drive, Bolder Road, Luton. LT7 8ER

Dear Sirs, Thank you for your Card Catalogue which arrived this morning. I would like to order your special parcel. (Paragraph) I understand you will send it on a sale or Return basis. Yours faithfully, Shirley Westerholt

From: 56 Green Lane, Woolacome, Dorset. WO4 1Gl

To: To-day's date $\quad$ John Yates Co. Ltd., Yates Nursery, Dulverton, Somerset. SU7 2DD

Dear Sir, will you please send me, free of charge, your illustrated Garden Furniture Catalogue as recently advertised in the Sunday Mirror. (Paragraph) I enclose a stamped addressed envelope. Yours faithfully, Simon st. Claire Enc.

\section{LESSON 53}

